\title{
A Visual Cultural Study of Pictorial Weekly in the Republican Period
}

\author{
CHEN Hua \\ Southwest University, Chongqing, China
}

\begin{abstract}
Peter Burke once said, using images as historical evidence could not only stand as proof of political events, economic trend, and social structure, but also as an illustration of the history of daily life, material culture, mental state, and physical body. Photography is the extension of human vision, the appearance of which has changed the way in which people see the world, molded the subject identity of modernity, and participated in the social construction of visual modernity. To witness the history is not the only purpose of studying on photograph-based pictorials in the republican period, for which it is more important to provide visual reference for the construction of China's modernization, and to witness the multiplicity, mobility, and inner-diversity of modernity.
\end{abstract}

Keywords: Pictorial Weekly, visual modernity, scopic regime, subject identity of modernity

\section{Introduction}

A pictorial usually contains a great number of images, and this is also its typical characteristic. According to different sources of images, pictorials could be divided into painting pictorials and photographic pictorials. Images on painting pictorials, with a typical example of Dianshizhai Huabao, are generally hand-painted, and are printed mainly by means of lithographic printing or block printing. But images on painting pictorials are unable to represent the reality precisely, because when being painted manually, they have been inevitably imposed the painter's subjective assumption on, and some of them even have been painted totally according to the painter's imagination. Nevertheless, photography, as a new kind of visual media, by virtue of its mechanical replication of the reality and images, has exerted profound influences on visual culture in modern times. With the rise and prosperity of photography in the republican period, painting pictorials have gradually withered away, whereas photographic pictorials, the combination of photography and printing, have reached its peak during the 1920 s to 1930 s.

As China's first weekly publication featuring photography, Pictorial Weekly was founded in 1925 by LIN Ze-cang, the initiator of China Photographic Society, then changed from weekly into fortnightly, and proclaimed its demise after the 8/13 Incident in 1937, with a total of 570 issues. Unlike specialized photography publications at a later time that only explore photography from the point of ontology, Pictorial Weekly, as a highly specialized photographic art publication, has promoted the influences of photography on the visual construction of the society in various forms, and expanded the social impacts of photography through publishing the current news and celebrity events, and holding China's earliest monthly photography competition. Thus, it is undoubted that Pictorial Weekly is of the characteristics of comprehensive pictorials.

CHEN Hua, Ph.D. candidate, School of Liberal Arts, Southwest University. 
However, at that time, no comprehensive photography pictorial of influence, like The Young Companion or The Pei-yang Pictorial News, were founded. Therefore, choosing Pictorial Weekly as the object of study is of unique value.

\section{Study Paradigms of Pictorials}

The initial study findings on pictorial mainly concentrate on reviewing and classifying the historical data, and in this respect, studies of A Ying, SA Kong-liao, and PENG Yong-xiang are most authoritative.

For the pictorials are the periodical which features images, different ways of interpreting images bring forth different paradigms of studying pictorial, which currently could be divided into two types: "mapping mode", which studies pictorials as the "history of painting"; "reproducing mode", which places emphasis on images' functions of signification and representation. And the difference between the two modes is just as HUANG Ke-wu (2003) has argued:

The viewpoint of "mapping" is that, since the image is the moment of history which has been faithfully captured, it can present the past that could not recorded or described in written materials. In coordination with "common sense", the "mapping" viewpoint have exerted influences on the cognition of visual materials of history for a long time. However, for the viewpoint of "reproducing", the "mapping" viewpoint ignores that the production and consumption of images, which are involved with the prospective and choices of observers, are of non-neutrality... Supporters of the "reproducing" viewpoint believe that, instead of regarding images as mirrors reflecting the reality, it is better to regard them as culture products, of which the producing, marketing and consuming (corresponding to the way in which images are presented, observed and interpreted) should all be explored. (Introduction)

We hold that the "reproducing mode" could also be called as the paradigm of studying the visual culture of pictorials.

The study paradigm of "mapping" argues that images in pictorials are historical materials of as much value as words, and the analysis of the content of pictorials could give people a grasp of the politics, economy, culture, culture, and other aspects in modern time of China. In this respect, the most representative study works are the three books authored and edited by CHEN Ping-yuan: Pictures of Late Qing Dynasty: Dianshizhai Huabao (2006), Pictures of Late Qing Dynasty: Besides Dianshizhai Huabao (2014), and Western Learning in the Late Qing Dynasty (2008). Studies made by CHEN Ping-yuan also involve the history of news, painting, and culture. He attempted to illustrate and elucidate the social custom, cultural ideological trend, and aesthetic taste the late Qing Dynasty. However, limited to the inter-explaining relation between images and words, studies of CHEN Ping-yuan did not refer to the representation function and signifying practice of images. As CHEN Ping-yuan himself said, "Just leave it to our reader, who are much wiser than us, how to extend the meaning and explore the profound connotations in sublime words" (CHEN \& XIA, 2014, p. 6). And other important study findings include The Visual Popularity of Modern Knowledge in China: Taking Dianshizhai Huabao as an Example (1990) by WANG Er-min, Drawing Conclusions: Illustration and the Pre-history of Mass Culture (1993) by Kahn Harold, and Joining the Global Imaginaire: The Shanghai Illustrated Newspaper Dianshizhai Huabao (2001) by Rudolf G. Wagner.

However, the above works refers little to the exploration into functions of signification and representation of images in pictorials from visual culture. Studies related to visual culture include the following works: The first is the six-volume Modern History of Chinese Image Journalism 1840-1919 (2012) edited by HAN Cong-yao. With a great number of pictures of the late Qing Dynasty and the republican period, the study work 
is special regarding the study on images as the interpretation of the significance and it believes images are the production of "significance" and the carrier of "exchange", which are effective media for the constitution and transmission of the significance. Hence, HAN Cong-yao proposed that the image is of three forms (technical form, constitutive form, and social form) and three fields for significance (image producing field, image field, and image transmission field). However, in terms of the case study on pictorials, it only focuses on images' value in the history of news. The second is The Distorting Mirror: Visual Modernity in China (2013) by PENG Li-jun. With the metaphor for distorting mirror, this book explores the multiple and complex way in which Chinese citizens see themselves in the collision between them and the rising visual culture during 1880s to 1930s. Referring to media and visual forms as lithographic pictorial, photography, advertisement, film, traditional Chinese opera, and acrobatics, this book analyzes a variety of visual reproduction and stresses out the complex interaction among them, and then proves that visual modernity is not an independent cultural phenomenon but related closely to cultural discourse in society. Meanwhile, this book also sees images as the field of producing significance. But the author of this book mainly focuses on the feministic perspective, and just explores pictorials as one of the forms of visual reproduction. The third is Image and Modernity: A Study of the Visual Culture in Chinese Modern Pictorials 1884-1937 (2008) by XU Pei. Based on the theory of visual culture, this article, starting with the visual representation of the "modernity" of images in pictorials, divides them into "narrative images" and "exhibitory images". The study of this article spans over two historical periods: the late Qing Dynasty and the republican period, accordingly its content involves two forms of pictorials: lithographic pictorial and photographic pictorial. It is undoubted that this kind of study method could provide a grander way to the investigation of the production of pictorials and relations between pictorials and visual culture and modernity. However, there are certain shortcomings in this method. Setting aside the reasonability of simply classifying various images in pictorials into two kinds of images, it could be argued that, for living up to the author's theoretical presupposition, whether the studies on pictorials should be carried out by ignoring the inter-textual relation between words and images, and leaving the production, transmission, and acceptance of images.

\section{Studies on Pictorial Weekly}

There are two methods to study pictorials: One is to study all kinds of pictorials, covering a wide range; the other is to specialize in one kind of pictorial and make in-depth inquiries into it. And between the two methods, this study adopted the latter one, and chose Pictorial Weekly as the study object on account of its visual culture attribute. Visual culture focuses on questions based on visual images, that is, questions about seeing and being seen, including such questions as what to see, who are seeing, how to see, where to see, and why to see. The focus of the studies on Pictorial Weekly is specifically referred to the subject of seeing, more specifically, it includes questions as how to construct visual subject that is of modernity, how to interpret images in pictorials, how to investigate in the inter-textual relation between words and images, how to analyze the seeing of representation, how the audience of pictorials create significance, and the correlation between visual technique, i.e., image reproduction and the history of seeing.

Specifically, it is embodied in the following aspects:

Firstly, photography, due to its characteristic of realism, has become the most representative media of modernity at that time. Hence, it is essential to explore, commencing on photography in the visual construction of modernity, how photography shaped the subject identity and scopic regime of modernity. 
Secondly, images, the same as words, are a kind of representation practice, so exploring photograph-based Pictorial Weekly in the context of cultural transmission is to explore comprehensively the representation system of visual significance from the encoding, decoding, and medium of significance, that is to say, to examine the audience's gaze, power, and other relevant knowledge, strategies with which the audience create significance, and the correlation between visual technique, i.e., image reproduction and the history of seeing.

Lastly, after classifying and interpreting, images in the Pictorial Weekly are divided, for emphasizing their representation of visual modernity, into four types: feminine images (the identity construction of modern female intellectuals), sports images (modernity project for stronger body and country), alien images (modernity imagination referring to the West), and war images (imagined community of modern nation-states).

\section{Conclusion}

Most of studies on pictorials are based on historical materials and prove the history with pictures. And this study on visual culture is started from photography, in this way, photography's visual construction for modernity can be explored as well, and the multiplicity, mobility, and inner-diversity of modernity could be witnessed, so as to find an effective way and a new method for interpreting studies on pictorials. Certainly, applying theories of modern visual culture and photography to study Pictorial Weekly in the republican period is an attempt to combine new theory with old materials, which, whether successful or not, could provide references for the current visual culture studies in China.

\section{References}

CHEN, P. Y. (2008). Western learning in the late Qing Dynasty. Hongkong: Joint Publishing (HK).

CHEN, P. Y. (2014). Pictures of late Qing Dynasty: Besides Dianshizhai huabao. Beijing: Oriental Publishing Center.

CHEN, P. Y., \& Xia, X. H. (2014). Pictures of late Qing Dynasty: Dianshizhai huabao. Beijing: Oriental Literature and Art Publishing House.

HAN, C. Y. (Ed.). (2012). Modern history of Chinese image journalism 1840-1919. Nanjing: Nanjing University Press.

HUANG, K. W. (Ed.). (2003). When images speak: Visual representation and cultural mapping in modern China. Taipei: Institute of Modern History, Academia Sinica.

Kahn, H. (1993). Drawing conclusions: Illustration and the pre-history of mass culture. In Reflections on reading history: Three academic speeches (pp. 89-100). Taipei: Institute of Modern History, Academia Sinica.

PENG, L. J. (2013). The distorting mirror: Visual modernity in China. (C. T. ZHANG \& Z. M. HUANG, Trans.). Shanghai: Shanghai Bookstore Publishing House.

Wagner, R. G. (2001). Joining the global imaginaire: The Shanghai illustrated newspaper Dianshizhai huabao. Beijing: Commercial Press.

WANG, E. M. (1990). The visual popularity of modern knowledge in China: Taking Dianshizhai huabao as an example. Bulletin of the Institute of Modern History, Academia Sinica, 19, 135-172.

XU, P. (2008). Image and modernity: A study of the visual culture in Chinese modern pictorials 1884-1937 (Doctorial dissertation, Sichuan University). 